\title{
Lethal and Sublethal Effects on Tamarixia triozae (Hymenoptera: Eulophidae), an Ectoparasitoid of Bactericera cockerelli (Hemiptera: Triozidae), of Three Insecticides Used on Solanaceous Crops
}

\author{
Sinue I. Morales, ${ }^{1}$ Ana M. Martínez, ${ }^{1}$ Elisa Viñuela, ${ }^{2}$ Juan M. Chavarrieta, ${ }^{1}$ \\ José I. Figueroa, ${ }^{1}$ Marcela I. Schneider, ${ }^{3}$ Fernando Tamayo, ${ }^{4}$ and Samuel Pineda ${ }^{1,5}$
}

\begin{abstract}
'Instituto de Investigaciones Agropecuarias y Forestales. Universidad Michoacana de San Nicolás de Hidalgo. Km. 9.5 Carretera Morelia-Zinapécuaro. 58880 Tarímbaro, Michoacán, Mexico, 2Protección de Cultivos, Escuela Técnica Superior de Ingeniería Agronómica, Alimentaria y de Biosistemas, Universidad Politécnica de Madrid (UPM), Madrid, Spain, ${ }^{3}$ Laboratorio de Ecotoxicología: Plaguicidas y Control Biológico. Centro de Estudios Parasitológicos y de Vectores (CEPAVE, CCT La Plata CONICET-UNLP), Bv. 120 s/n. 1900. La Plata, Buenos Aires, Argentina, ${ }^{4}$ Secretaría de Desarrollo Agroalimentario y Rural. Centro de Sanidad Vegetal de Guanajuato. Vicente Rodríguez s/n Frac. La Paz. 36560, Irapuato, Guanajuato, Mexico, and ${ }^{5}$ Corresponding author, e-mail: spineda us@yahoo.com
\end{abstract}

Subject Editor: Joseph Munyaneza

Received 12 November 2017; Editorial decision 30 January 2018

\begin{abstract}
Lethal and sublethal effects of refined soybean oil, imidacloprid, and abamectin on Tamarixia triozae (Burks; Hymenoptera: Eulophidae) were assessed after exposure of the eggs, larvae, and pupae of this parasitoid to three concentrations of these active substances: the $\mathrm{LC}_{50}$ for fourth-instar Bactericera cockerelli (Sulc.; Hemiptera:Triozidae) and $50 \%$ and $100 \%$ of the minimum field-registered concentration (MiFRC). Soybean oil caused 26-61\% mortality in T. triozae eggs and 6-19\% in larvae; mortality in both eggs and larvae was $\leq 19 \%$ for imidacloprid and $4-100 \%$ for abamectin. All three compounds caused $<18 \%$ mortality of T. triozae pupae, with the exception of the abamectin $50 \%$ $(47 \%)$ and $100 \%$ (72\%) MiFRC. The mortality of larvae and pupae derived from treated eggs was $\leq 39 \%$ for all three insecticides, and that of pupae derived from treated larvae was $\leq 10 \%$. In general, emergence of adults developed from treated eggs, larvae, and pupae was affected more by abamectin than by the other treatments. The proportion of females derived from all three development stages was not affected by treatment with the compounds, except when the parasitoid was treated as larvae with the soybean oil 100 and 50\% MiFRC (66 and 68\%, respectively) or when treated as pupae with the imidacloprid LC $_{50}$ and $100 \%$ MiFRC ( 60\%). Female longevity was generally higher than that of males. The use of imidacloprid, soybean oil, and abamectin in combination with $T$. triozae for pest control may be effective when the parasitoid is in the pupal stage because this stage is less susceptible than other immature stages.
\end{abstract}

Key words: synovigenic ectoparasitoid, biological control, life parameter, tomato/potato psyllid

The tomato or potato psyllid Bactericera cockerelli (Sulc.; Hemiptera: Triozidae) is a highly polyphagous insect that feeds on more than 40 plant species from over 20 families but shows a strong preference for certain solanaceous crops (Yang et al. 2010). This species is the principal vector of the bacterium Candidatus Liberibacter solanacearum (a.k.a. Ca. Liberibacter psyllaurous), which is responsible for zebra chip (ZC) disease in potato (Solanum tuberosum L.) (Munyaneza et al. 2007), tomato (Solanum lycopersicum L.) (Levy et al. 2011), and pepper (Capsicum annuum L.) (Munyaneza and Sengoda 2009) crops, all three species (Solanales: Solanaceae).
In Mexico, control of B. cockerelli populations has principally been realized through the use of synthetic insecticides belonging to the carbamate, organophosphate, pyrethroid, and spinosyn groups (Dávila et al. 2012), though other compounds such as imidacloprid, thiamethoxam, abamectin, spirotetramat, spiromesifen, and pyriproxyfen are also occasionally applied. However, the intensive use of pesticides has compromised their effectiveness, especially due to the development of resistance in the pest to many of the main active substances available on the market (Dávila et al. 2012). To avoid this problem, alternative control methods have been proposed, 
including the use of selective insecticides such as soybean oil and abamectin (both naturally derived) and imidacloprid (neonicotinoid) together with parasitoid biological control.

Soybean (Glycine max L.) oil, which is extracted from seeds, is safe and not persistent in the ecosystem (Lee et al. 2005). Similar to other oil-based products, soybean oil acts by causing insect death through contact via disruption of gas exchange or epidermal cell membrane function as well as spiracle obstruction, which causes asphyxia (Pless et al. 1995). Abamectin, the mixture of avermectin $\mathrm{B}_{1 \mathrm{a}}$ and $\mathrm{B}_{1 \mathrm{~b}}$, is produced during fermentation by the soil actinomycete Streptomyces avermitilis (ex Burg et al.) Kim and Goodfellow (Lasota and Dybas 1991). This biopesticide persistently stimulates the central nervous system of insects through interaction with $\gamma$-aminobutyric acid receptors and blocks signal transmission at the neuromuscular junction (Lasota and Dybas 1991). Imidacloprid is a neonicotinoid insecticide that belongs to group 4A according to Insecticide Resistance Action Committee (IRAC) mode of action classification (IRAC 2017). This compound binds to insect nicotinic acetylcholine receptors and is effective both systemically and through contact (Zhang et al. 2000). These three pesticides are highly effective against soft-bodied insects, including B. cockerelli (Bujanos et al. 2005, Gharalari et al. 2009, Luna-Cruz et al. 2011).

Tamarixia triozae (Burks; Hymenoptera: Eulophidae) is the most important ectoparasitoid of B. cockerelli (Martínez et al. 2015). In addition, as a synovigenic parasitoid, T. triozae females feed on the host's haemolymph (host feeding), which also contributes to overall mortality (Morales et al. 2013). Therefore, this feeding behavior appears to enhance the potential of T. triozae as a biological control agent. However, few studies have addressed the toxicity of insecticides toward T. triozae, and most existing studies only focused on acute toxicity (Luna-Cruz et al. 2011, 2015; Liu et al. 2012; Martínez et al. 2015). Nonetheless, as the importance of other adverse effects has been highlighted by modern ecotoxicology (Desneux et al. 2007), a complete analysis of their impacts requires that the potential sublethal effects caused by insecticides on this parasitoid must be considered in addition to the lethal effects.

The objective of this study was to evaluate the lethal (direct mortality) and sublethal (adult emergence, sex ratio, and adult longevity) effects of three insecticides on immature stages of T. triozae: two synthetic products still effective against the pest, abamectin and imidacloprid, and one natural product, soybean seed oil. These three insecticides are commonly used to control B. cockerelli occurring on solanaceous crops in Mexico.

\section{Materials and Methods}

\section{Insects}

The insects used in the assays derive from permanent colonies of B. cockerelli and T. triozae maintained at the Entomology Laboratory of the Instituto de Investigaciones Agropecuarias y Forestales, Universidad Michoacana de San Nicolás de Hidalgo, Mexico. The rearing of $B$. cockerelli was completed within a greenhouse $\left(16-30^{\circ} \mathrm{C}, 60 \%\right.$ relative humidity [RH] , and an $\sim 14: 10$ [L:D] h photoperiod) using tomato plants (Río Grande) for feeding of nymphs and adults and as an oviposition substrate (Martínez et al. 2015). Rearing of the parasitoid T. triozae was performed in the laboratory $\left(25^{\circ} \mathrm{C}, 56 \% \mathrm{RH}\right.$, and a $12: 12$ [L: D] h photoperiod) by using tomato plants infested with a mixture of third-, fourth-, and fifth-instar nymphs of $B$. cockerelli suitable for the development of immature stages and by providing adults with honey ad libitum (Morales et al. 2013, Martínez et al. 2015).

\section{Chemicals}

The commercial products AbaKrone $(1.8 \%$ abamectin, emulsion concentrate), ImidaKrone (30.2\% imidacloprid, suspension concentrate), and EPA 90 (90\% refined soybean seed oil, emulsion concentrate) were used in this study. EPA 90, registered in Mexico under the code RSCO-INAC-0103F-301-009-090, is identical to that registered under code 031605 by the U.S. Environmental Protection Agency. All of these insecticides were obtained from Biokrone S. A de C.V., Celaya, Guanajuato, Mexico.

\section{Lethal and Sublethal Effects}

The lethal effects of abamectin, imidacloprid, and soybean oil on the eggs, larvae, and pupae of T. triozae were examined separately using parasitized $B$. cockerelli nymphs containing parasitoids in these different development stages. The methodology of Martínez et al. (2015) was followed to obtain T. triozae eggs, larvae, and pupae of the same age. In brief, tomato leaflets bearing 15 fourth-instar B. cockerelli individuals ( $\leq 48 \mathrm{~h}$ after ecdysis) were offered to $13-\mathrm{d}-$ old parasitoid females with previous copulation for $6 \mathrm{~h}$; this age was chosen because it is at which maximum oviposition activity occurs in this species. The leaflets were carefully examined under a stereoscopic microscope; nymphs that had not been parasitized were removed using a small brush.

Parasitized nymphs of $B$. cockerelli were incubated under the laboratory conditions described above for $T$. triozae rearing to obtain larval and pupal stages of T. triozae ( 2 and $5 \mathrm{~d}$ after parasitization, respectively); parasitized nymphs containing the egg stage of the parasitoid were used the same day the parasitization occurred. Leaflets containing $B$. cockerelli nymphs parasitized with eggs $(<10 \mathrm{~h}$ old), larvae $(<12 \mathrm{~h}$ old) or pupae $(<12 \mathrm{~h}$ old $)$ of $T$. triozae were dipped for $5 \mathrm{~s}$ into one of three concentrations of abamectin $(9,4.5$, or $0.03 \mathrm{mg}$ of active ingredient [AI]/liter), imidacloprid (260, 130, or $3 \mathrm{mg}[\mathrm{AI}] /$ liter), or soybean oil $(1,620,810$, or $443 \mathrm{mg}$ [AI]/liter). Immersion is a common practice in studies assessing the efficacy of pesticides against pests or their non-target effects against natural enemies (Hassan 1977). The concentrations bioassayed correspond to the minimum field-registered concentration (100\% MiFRC), half that concentration $(50 \% \mathrm{MiFRC})$, and the median lethal concentration $\left(\mathrm{LC}_{50}\right)$ for B. cockerelli fourth-instar nymphs, respectively (Bujanos et al. 2005). To enhance the wetting of the leaflet, the surfactant Tween 20 was used at $0.01 \%(w / v)$. Control leaflets were dipped in distilled water plus surfactant at $0.01 \%$. Six replicates were performed for each concentration of each insecticide as well as each immature developmental stage bioassayed. Ten parasitized fourth-instar nymphs of $B$. cockerelli containing each developmental stage of T. triozae were considered to be one replicate.

The treated tomato leaflets were dried at room temperature in a well-ventilated area ( $2 \mathrm{~h}$ after treatment). Next, each leaflet was individually transferred to an insect-free frame box $(14 \times 14 \times 14 \mathrm{~cm})$ and maintained under the laboratory conditions described above. The mortality of both the eggs and larvae of the parasitoid was recorded every $24 \mathrm{~h}$ post-treatment until the formation of pupae. Eggs and larvae that were flabby or dried were considered dead. Mortality of pupae derived from treated eggs and larvae, as well as that of treated pupae, was recorded after emergence of adult parasitoids.

The numbers of parasitoid adults that emerged from treated nymphs were recorded at 14,11 , and $7 \mathrm{~d}$ after insecticide application of the egg, larval, and pupal stages of the parasitoid, respectively. After emergence, the sex ratio of adults was calculated as the percentage of females [females/(females + males $) \times 100]$. Adult longevity was also recorded. For this, the adults that emerged from 
each treated immature stage as well as in each insecticide treatment at different concentrations were placed in a cylindrical plastic tube $(5.5 \mathrm{~cm}$ in diameter and $10.5 \mathrm{~cm}$ in height) that was open at both ends. The top of the cylinder was covered with a fine mesh screen to permit air circulation and to prevent the insects from escaping. In both the control and treatment groups, the parasitoids were fed small drops of pure honey deposited on the inner cylinder walls and were given water ad libitum. The adults were checked every $24 \mathrm{~h}$ until they died.

\section{Data Analysis}

The experiment comprised a $4 \times 3$ factorial design with treatment (four levels: control, abamectin, imidacloprid, and soybean oil) and treated stage (three levels: egg, larva, and pupa) as the main factors. The data were subjected to analysis of variance (ANOVA) after checking for normality and homoscedasticity. Analyses were performed using the fixed-effects model, with the least significant difference (LSD) multiple range test $(P<0.05)$ to separate means (SAS/ STAT version 9.3; SAS Institute, Cary, NC).

\section{Results}

\section{Lethal Effects}

\section{Treated Eggs}

No significant differences in the mortality of eggs were observed among the soybean oil concentrations, but all of the groups treated with soybean oil showed significant differences from the controls $(F=10.49 ; \mathrm{df}=7,33 ; P=0.001)$ (Table 1$)$. For imidacloprid, no significant differences were observed between the highest concentration ( $1 \%$ mortality) and the controls $(0 \%)$. Regarding abamectin, mortality $(6 \%)$ was only assessed at the lowest concentration $(0.03 \mathrm{mg}$ $[\mathrm{AI}] /$ liter) because this compound caused $100 \%$ mortality of host nymphs at the other two concentrations evaluated.
No mortality was observed for T. triozae larvae obtained from eggs treated with soybean oil, but significant effects ( $F=10.51$; $\mathrm{df}=7,33 ; P=0.001$ ) were observed for imidacloprid (mortality ranging from 4 to $25 \%$ ) and the lowest concentration of abamectin $(39 \%)$ (Table 1). No significant differences in mortality were found between parasitoid pupae derived from treated eggs and those derived from control eggs $(F=0.54 ; \mathrm{df}=7,33 ; P=0.790)$.

\section{Treated Larvae}

The insecticides soybean oil, imidacloprid, and abamectin significantly affected $(F=4.24 ; \mathrm{df}=7,40 ; P=0.001)$ the larval stage of T. triozae (Table 1). Mortality due to soybean oil and imidacloprid was very similar, ranging from 11 to $19 \%$ for both insecticides, except for the lowest concentration of soybean oil, for which $6 \%$ mortality was observed. No significant differences in mortality were found between larvae treated with the two lowest concentrations of abamectin $(\leq 4.5 \%)$ and the control $(2 \%)$. Conversely, the highest concentration of abamectin caused $100 \%$ mortality in B. cockerelli nymphs. The mortality of $T$. triozae pupae obtained from treated larvae was only higher than the control at the three concentrations of imidacloprid $(\sim 10 \%)(F=3.23 ; \mathrm{df}=8,40 ; P=0.006)$ (Table 1$)$.

\section{Treated Pupae}

Compared with the controls, soybean oil did not cause any effect $(P>0.05)$ on $T$. triozae pupae at any of the concentrations tested. Imidacloprid at 130 and $260 \mathrm{mg}(\mathrm{AI}) /$ liter caused $<12 \%$ mortality $(8.50 \pm 1.48$ and $11.83 \pm 1.48$, respectively, for each concentration), though no mortality was recorded at $3 \mathrm{mg}(\mathrm{AI}) /$ liter. Pupae treated with abamectin showed an increase in mortality that appeared to be dose dependent: the mean percentages of pupal mortality caused by abamectin at $0.03,4.5$, and $9 \mathrm{mg}(\mathrm{AI}) /$ liter were $17.16 \pm 1.48$, $46.66 \pm 1.48 \%$, and $71.66 \pm 1.48 \%$, respectively. With the exception

Table 1. Mortality (mean \pm SE) of eggs and larvae of Tamarixia triozae when parasitized fourth-instar Bactericera cockerelli were treated with three insecticides by dipping

\begin{tabular}{|c|c|c|c|c|}
\hline \multirow[t]{2}{*}{ Treatment } & \multirow[t]{2}{*}{ Concn (mg [AI]/liter) } & \multicolumn{3}{|c|}{ Mortality (\%) } \\
\hline & & Treated eggs & Larvae from treated eggs & Pupae from treated eggs \\
\hline Control & 0 & $0 \pm 0 \mathrm{~A}$ & $0 \pm 0 \mathrm{~A}$ & $0 \pm 0 \mathrm{~A}$ \\
\hline \multirow[t]{3}{*}{ Soybean oil } & 443 & $26 \pm 2 C$ & $0 \pm 0 \mathrm{~A}$ & $0 \pm 0 \mathrm{~A}$ \\
\hline & 810 & $36 \pm 2 C$ & $0 \pm 0 \mathrm{~A}$ & $0 \pm 0 \mathrm{~A}$ \\
\hline & 1,620 & $61 \pm 1 \mathrm{C}$ & $2 \pm 2 \mathrm{~A}$ & $0 \pm 0 \mathrm{~A}$ \\
\hline \multirow[t]{3}{*}{ Imidacloprid } & 3 & $12 \pm 1 B$ & $3 \pm 1 \mathrm{AB}$ & $0 \pm 0 \mathrm{~A}$ \\
\hline & 130 & $6 \pm 1 B$ & $7 \pm 1 B$ & $1 \pm 1 \mathrm{~A}$ \\
\hline & 260 & $1 \pm 1 \mathrm{~A}$ & $25 \pm 1 \mathrm{C}$ & $1 \pm 1 \mathrm{~A}$ \\
\hline \multirow[t]{4}{*}{ Abamectin } & 0.03 & $6 \pm 1 \mathrm{~B}$ & $39 \pm 1 C$ & $2 \pm 1 \mathrm{~A}$ \\
\hline & 4.5 & $\mathrm{ND}$ & ND & ND \\
\hline & 9 & ND & ND & ND \\
\hline & & Treated larvae & - & Pupae from treated larvae \\
\hline Control & 0 & $2 \pm 1 \mathrm{~A}$ & - & $0 \pm 0 \mathrm{~A}$ \\
\hline \multirow[t]{3}{*}{ Soybean oil } & 443 & $6 \pm 1 \mathrm{AB}$ & - & $2 \pm 1 \mathrm{~A}$ \\
\hline & 810 & $19 \pm 1 C$ & - & $2 \pm 1 \mathrm{~A}$ \\
\hline & 1,620 & $15 \pm 1 \mathrm{~B}$ & - & $2 \pm 1 \mathrm{~A}$ \\
\hline \multirow[t]{3}{*}{ Imidacloprid } & 3 & $11 \pm 1 \mathrm{~B}$ & - & $10 \pm 1 \mathrm{~B}$ \\
\hline & 130 & $19 \pm 1 \mathrm{BC}$ & - & $8 \pm 1 \mathrm{~B}$ \\
\hline & 260 & $16 \pm 1 \mathrm{BC}$ & - & $9 \pm 1 B$ \\
\hline \multirow[t]{3}{*}{ Abamectin } & 0.03 & $4 \pm 1 \mathrm{AB}$ & - & $3 \pm 2 \mathrm{~A}$ \\
\hline & 4.5 & $0 \pm 0 \mathrm{~A}$ & - & $1 \pm 1 \mathrm{~A}$ \\
\hline & 9 & ND & - & ND \\
\hline
\end{tabular}

Means within columns that are followed by the same letter are not significantly different $(P>0.01)$. ND, Not determined because $100 \%$ mortality was observed for parasitized Bactericera cockerelli nymphs. 
of the lowest concentration of imidacloprid, the mortality caused by the other two concentrations of this compound and all of the abamectin doses differed significantly $(F=27.28$; df $=19,100$; $P=0.006)$ from the controls $(0 \%)$.

\section{Sublethal Effects}

Emergence of T. triozae adults developed from treated eggs and larvae declined significantly $(F=10.35 ; \mathrm{df}=26,123 ; P=0.001)$ when parasitized fourth-instar $B$. cockerelli were treated with the three compounds (Table 2). When the parasitoid eggs were treated with soybean oil and imidacloprid, adult emergence declined 1.6- to 3.6fold and 1.4- to 1.6-fold compared with the control, respectively, whereas adult emergence decreased 11-fold when eggs were treated with abamectin at the lowest concentration (Table 2).

Emergence of adults obtained from larvae treated with soybean oil and abamectin was only significantly reduced at 810 and $4.5 \mathrm{mg}$ (AI)/liter relative to the controls (1.6- and 10-fold, respectively) (Table 2). In the case of imidacloprid, adult emergence was significantly reduced (by 1.6-fold) at 130 and $260 \mathrm{mg}$ (AI)/liter (Table 2). The emergence of adult $T$. triozae obtained from treated pupae was very similar for soybean oil and imidacloprid ( 90-100\%), and no significant differences were observed compared with the controls (Table 2). With regard to abamectin, the lowest two concentrations significantly reduced adult emergence (2-and 5-fold) compared with the controls.

The sex ratio of $T$. triozae was significantly affected when insects were treated as larvae $(F=2.1 ; \mathrm{df}=7,340 ; P=0.043)$ with concentrations of 810 and $1620 \mathrm{mg}(\mathrm{AI}) / \mathrm{liter}$ soybean oil (66 and $68 \%$ females, respectively) or when treated as pupae $(F=4.03$; $\mathrm{df}=9$, 47; $P=0.001)$ with 3 and $260 \mathrm{mg}(\mathrm{AI}) /$ liter imidacloprid (60 and $58 \%$ females, respectively). The effect was a reduction in the female proportion compared to the control insects (83-84\% females) (Table 3). When parasitoids were treated as eggs, the percentage of females emerging was not significantly altered $(F=1.98 ; \mathrm{df}=7,230$; $P=0.058)$ by any concentration of either soybean oil or imidacloprid or by the lower concentration of abamectin (range 61-91\%) compared to the control $(78 \%)$.

The longevity of adults obtained from treated immature stages of T. triozae depended on the concentration of insecticide used (Table 4). Regardless of the parasitoid stage, the longevity of males was generally between 22 and $37 \mathrm{~d}$. Significant differences $(F=3.66 ; \mathrm{df}=19,199 ; P=0.001)$ were only observed in males emerging from larvae treated with $0.03 \mathrm{mg}(\mathrm{AI}) /$ liter abamectin and those derived from pupae treated with $260 \mathrm{mg}$ (AI)/liter imidacloprid and 0.03 and $9 \mathrm{mg}(\mathrm{AI}) /$ liter abamectin, for which the longevity was between 17 and $21 \mathrm{~d}$.

Table 2. Emergence of Tamarixia triozae adults (mean \pm SE) from treated (by dipping) egg, larval, and pupal stages when parasitizing fourth-instar Bactericera cockerelli

\begin{tabular}{|c|c|c|c|c|}
\hline \multirow[t]{2}{*}{ Treatment } & \multirow[t]{2}{*}{ Concn (mg [AI]/liter) } & \multicolumn{3}{|c|}{ Adult emergence from treated developmental stages ( $\%)$} \\
\hline & & Egg & Larva & Pupa \\
\hline Control & 0 & $100 \pm 0 \mathrm{Aa}$ & $96 \pm 2 \mathrm{Aa}$ & $100 \pm 0 \mathrm{Aa}$ \\
\hline \multirow[t]{3}{*}{ Soybean oil } & 443 & $63 \pm 3 \mathrm{Ba}$ & $80 \pm 4 \mathrm{ABa}$ & $100 \pm 0 \mathrm{Aa}$ \\
\hline & 810 & $50 \pm 12 \mathrm{Ba}$ & $61 \pm 8 \mathrm{Ba}$ & $100 \pm 0 \mathrm{Ab}$ \\
\hline & 1,620 & $28 \pm 2 \mathrm{Ca}$ & $68 \pm 5 \mathrm{ABb}$ & $100 \pm 0 \mathrm{Ab}$ \\
\hline \multirow[t]{3}{*}{ Imidacloprid } & 3 & $71 \pm 4 \mathrm{Ba}$ & $78 \pm 2 \mathrm{ACa}$ & $100 \pm 0 \mathrm{Aa}$ \\
\hline & 130 & $65 \pm 7 \mathrm{Ba}$ & $59 \pm 5 \mathrm{BCa}$ & $92 \pm 4 \mathrm{Aa}$ \\
\hline & 260 & $62 \pm 6 \mathrm{Ba}$ & $60 \pm 6 \mathrm{BCa}$ & $88 \pm 3 \mathrm{Aa}$ \\
\hline \multirow[t]{3}{*}{ Abamectin } & 0.03 & $9 \pm 6 \mathrm{Da}$ & $71 \pm 3 \mathrm{ABb}$ & $83 \pm 8 \mathrm{Ab}$ \\
\hline & 4.5 & ND & $10 \pm 0 \mathrm{Da}$ & $53 \pm 8 \mathrm{Bb}$ \\
\hline & 9 & ND & ND & $28 \pm 9 B$ \\
\hline
\end{tabular}

Means within columns (capital letters) and within rows (lowercase letters) that are followed by the same letter are not significantly different $(P>0.01)$. ND, Not determined because $100 \%$ mortality was observed for parasitized Bactericera cockerelli nymphs.

Table 3. Adult sex ratios (means \pm SE) of Tamarixia triozae derived from egg, larval, and pupal stages when parasitized fourth-instar Bactericera cockerelli were treated with three insecticides by dipping

\begin{tabular}{|c|c|c|c|c|}
\hline \multirow[t]{2}{*}{ Treatment } & \multirow[t]{2}{*}{ Concn (mg [AI]/liter) } & \multicolumn{3}{|c|}{ Sex ratio ( $\%$ female) from treated developmental stage } \\
\hline & & Eggs & Larvae & Pupae \\
\hline Control & 0 & $78 \pm 5 \mathrm{a}$ & $84 \pm 5 b$ & $83 \pm 5 b$ \\
\hline \multirow[t]{3}{*}{ Soybean oil } & 443 & $78 \pm 9 \mathrm{a}$ & $75 \pm 6 a b$ & $87 \pm 4 b$ \\
\hline & 810 & $93 \pm 10 a$ & $68 \pm 8 \mathrm{a}$ & $85 \pm 5 b$ \\
\hline & 1,620 & $61 \pm 10 \mathrm{a}$ & $66 \pm 7 a$ & $85 \pm 6 b$ \\
\hline \multirow[t]{3}{*}{ Imidacloprid } & 3 & $79 \pm 6 \mathrm{a}$ & $87 \pm 5 b$ & $60 \pm 6 a$ \\
\hline & 130 & $77 \pm 6 a$ & $74 \pm 7 a b$ & $82 \pm 5 b$ \\
\hline & 260 & $97 \pm 6 \mathrm{a}$ & $73 \pm 7 \mathrm{ab}$ & $58 \pm 7 \mathrm{a}$ \\
\hline \multirow[t]{3}{*}{ Abamectin } & 0.03 & $91 \pm 1 \mathrm{a}$ & $91 \pm 4 b$ & $74 \pm 6 a b$ \\
\hline & 4.5 & ND & ND & $84 \pm 6 b$ \\
\hline & 9 & ND & ND & $94 \pm 6 b$ \\
\hline
\end{tabular}

Means within columns (lowercase letters) followed by the same letter do not differ significantly $(P>0.01)$. ND, Not determined because $100 \%$ mortality was observed for parasitized Bactericera cockerelli nymphs. 
Table 4. Longevity (days \pm SE) of Tamarixia triozae adults derived from egg, larval, and pupal stages when parasitized fourth-instar Bactericera cockerelli were treated with three insecticides by dipping

\begin{tabular}{|c|c|c|c|c|c|c|c|}
\hline \multirow[t]{3}{*}{ Treatment } & \multirow[t]{3}{*}{ Concn (mg $[\mathrm{AI}] /)$} & \multicolumn{6}{|c|}{ Longevity of Tamarixia triozae adults developing from different immature stages (d) } \\
\hline & & \multicolumn{2}{|c|}{ Egg } & \multicolumn{2}{|c|}{ Larva } & \multicolumn{2}{|c|}{ Pupa } \\
\hline & & Male & Female & Male & Female & Male & Female \\
\hline Control & 0 & $27 \pm 1 \mathrm{ABa}$ & $23 \pm 1 \mathrm{ABa}$ & $33 \pm 1 \mathrm{Ba}$ & $42 \pm 1 \mathrm{Ba}$ & $32 \pm 1 \mathrm{Ba}$ & $34 \pm 1 \mathrm{Ba}$ \\
\hline \multirow[t]{3}{*}{ Soybean oil } & 443 & $15 \pm 1 \mathrm{Aa}$ & $25 \pm 1 \mathrm{ABa}$ & $27 \pm 1 \mathrm{ABa}$ & $32 \pm 1 \mathrm{ABa}$ & $25 \pm 1 \mathrm{ABa}$ & $22 \pm 1 \mathrm{Aa}$ \\
\hline & 810 & ND & $43 \pm 1 \mathrm{CE}$ & $25 \pm 1 \mathrm{ABa}$ & $40 \pm 1 \mathrm{Bb}$ & $24 \pm 1 \mathrm{ABa}$ & $30 \pm 1 \mathrm{BDa}$ \\
\hline & 1,620 & $25 \pm 1 \mathrm{ABa}$ & $30 \pm 1 \mathrm{BCa}$ & $27 \pm 1 \mathrm{ABa}$ & $31 \pm 1 \mathrm{ABa}$ & $23 \pm 1 \mathrm{ABa}$ & $23 \pm 1 \mathrm{ACDa}$ \\
\hline \multirow[t]{3}{*}{ Imidacloprid } & 3 & $32 \pm 1 \mathrm{Ba}$ & $33 \pm 1 \mathrm{CDEa}$ & $22 \pm 1 \mathrm{ABa}$ & $33 \pm 1 \mathrm{ABa}$ & $25 \pm 1 \mathrm{ABa}$ & $29 \pm 1 \mathrm{BCa}$ \\
\hline & 130 & $27 \pm 1 \mathrm{ABa}$ & $35 \pm 1 \mathrm{CDEa}$ & $24 \pm 1 \mathrm{ABa}$ & $28 \pm 1 \mathrm{Aa}$ & $22 \pm 1 \mathrm{ABa}$ & $36 \pm 1 \mathrm{Ba}$ \\
\hline & 260 & $\mathrm{ND}$ & $44 \pm 1 \mathrm{E}$ & $26 \pm 1 \mathrm{ABa}$ & $30 \pm 1 \mathrm{ABa}$ & $18 \pm 1 \mathrm{Aa}$ & $32 \pm 1 \mathrm{Bb}$ \\
\hline \multirow[t]{3}{*}{ Abamectin } & 0.03 & $30 \pm 1 \mathrm{ABa}$ & $16 \pm 1 \mathrm{Aa}$ & $20 \pm 1 \mathrm{Aa}$ & $26 \pm 1 \mathrm{Aa}$ & $21 \pm 1 \mathrm{Aa}$ & $20 \pm 1 \mathrm{Aa}$ \\
\hline & 4.5 & - & - & - & - & $37 \pm 1 \mathrm{Ba}$ & $25 \pm 1 \mathrm{ACDa}$ \\
\hline & 9 & - & - & - & - & $17 \pm 1 \mathrm{Aa}$ & $27 \pm 1 \mathrm{ABCa}$ \\
\hline
\end{tabular}

Means within columns (capital letters) and within rows (lowercase letters) for each stage (egg, larva and pupa) that are followed by the same letter do not differ significantly $(P>0.01)$. ND, Not determined because males died between 5 and $7 \mathrm{~d}$ after emergence, before the start of the bioassay. - , Death of Bactericera cockerelli nymphs containing eggs or larvae of the parasitoid Tamarixia triozae.

Female longevity varied between 20 and $40 \mathrm{~d}$ for all insecticides, their concentrations, and immature parasitoid life stages tested (Table 4), with no significant difference from the control $(23,42$, and $34 \mathrm{~d}$ for females obtained from eggs, larvae, and pupae, respectively). However, there were three exceptions: 1) females obtained from eggs treated with $810 \mathrm{mg}(\mathrm{AI}) /$ liter soybean oil or 3, 130, or $260 \mathrm{mg}(\mathrm{AI}) /$ liter imidacloprid lived significantly longer than the controls; 2) the controls lived significantly longer than females obtained from larvae treated with $130 \mathrm{mg}(\mathrm{AI}) /$ liter imidacloprid or $0.03 \mathrm{mg}(\mathrm{AI}) /$ liter abamectin; and 3) the controls lived significantly longer than females obtained from pupae treated with 443 or 1,620 mg (AI)/liter soybean oil or 0.03 or $4.5 \mathrm{mg}(\mathrm{AI}) /$ liter abamectin.

For each developmental stage of the parasitoid T. triozae, no significant differences in longevity were observed between males and females across all treatments, with the exception of adults obtained from larvae treated with $810 \mathrm{mg}(\mathrm{AI}) /$ liter soybean oil $(F=1.91 ; \mathrm{df}=15,57$; $P=0.041)$ and those obtained from pupae treated with $260 \mathrm{mg}(\mathrm{AI}) /$ liter imidacloprid $(F=2.24 ; \mathrm{df}=19,72 ; P=0.007)$; in these cases, the longevity of males was significantly shorter than that of females.

\section{Discussion}

Most studies regarding the lethal and sublethal effects of pesticides on parasitoids have been conducted primarily on the adult stage (the most exposed stage), and comparatively little has been published on immature stages inside the host (the most protected stages). Moreover, it has been reported that parasitoids are less affected when treated at older stages (Stansly and Liu 1997, Sohrabi et al. 2012). Our results, however, showed that the susceptibility of T. triozae depended on its developmental stage and on the insecticide applied. For instance, the strength of the effects caused by soybean oil and imidacloprid was generally egg > larva > pupa, whereas the strength of the effects of the two higher concentrations of abamectin showed the opposite pattern (pupa > larva > egg). In addition to the mortality caused by the three compounds to the three immature stages of T. triozae, imidacloprid and abamectin caused significant mortality to larvae obtained from treated eggs. This most likely reflects the fact that hatching larvae can be contaminated by these compounds as they chew their way out of the egg and subsequently contact the treated surface.
There is no information available in the literature about the lethal effects of soybean oil, imidacloprid, and abamectin on the egg and larval stages of the ectoparasitoid T. triozae, though many studies have been conducted on the lethal effects of the above-mentioned compounds on the immature stages of endoparasitoids. In this regard, imidacloprid and abamectin were found to cause 32 and $51 \%$ mortality, respectively, to the preimaginal 'egg-larval' stage of the parasitoid Trichogramma pretiosum (Riley; Hymenoptera: Trichogrammatidae), with both compounds causing 30\% mortality to the prepupal stage (Carvalho et al. 2003). For the larvae of the ectoparasitoid Tamarixia radiata (Waterston; Hymenoptera: Eulophidae), imidacloprid at a concentration of $40 \mathrm{mg}$ (AI)/liter resulted in high $(93 \%)$ mortality when parasitized fourth-instar Diaphorina citri (Kuwayama; Hemiptera: Psyllidae) nymphs were treated by spraying (Santos et al. 2015). In contrast, low mortality of T. triozae larvae at the two highest concentrations of this compound (130 and $260 \mathrm{mg}[\mathrm{AI}] /$ liter) (between 16 and 19\%) was observed in our study, which can be taken as evidence of a higher tolerance to this compound or differences in mortality based on the mode of application.

Similar to our study, a high concentration (2 liter/ha) of a mineral oil (BiolidE) caused 13\% mortality to larvae of the ectoparasitoid Aphytis melinus (DeBach; Hymenoptera: Aphelinidae) when parasitizing nymphs of the oleander scale Aspidiotus nerii (Bouche; Hemiptera: Diaspididae) (Biondi et al. 2015). In contrast, mineral oil (Sunspray) resulted in 98, 84, and 55\% mortality to eggs, young larvae, and old larvae, respectively, of Encarsia pergandiella (Howard; Hymenoptera: Aphelinidae) when parasitizing nymphs of Bemisia argentifolii (Bellows \& Perring; Hemiptera: Aleyrodidae) (Stansly and Liu 1997).

In the present study, the pupal stage of T. triozae was the least susceptible to both soybean oil and imidacloprid. This was likely because T. triozae is an ectoparasitoid; thus, and at the end of its development, it fixes the remains of the dead psyllid nymph to the plant surface to pupate under it as a protective barrier. However, some studies have reported that other mineral oils and imidacloprid cause moderate to high mortality to both endo- and ectoparasitoids at this developmental stage. For example, $99 \%$ mortality to En.pergandiella pupae was found when the nymphs of its host, $B$. argentifolii, were treated with a low concentration of Sunspray $(2.9 \mathrm{mg}$ 
[AI]/liter) (Stansly and Liu 1997). Additionally, high concentrations of imidacloprid (40 mg [AI]/liter and 1 liter/ha) resulted in 63 and $100 \%$ mortality to T. radiata (Santos et al. 2015) and T. triozae (Luna-Cruz et al. 2011) pupae treated by spraying and leaf dipping, respectively. This compound also caused variable mortality (between 20 and $90 \%$ ) to the pupae of the aphelinids Eretmocerus mundus Mercet, Encarsia inaron (Walker), and Eretmocerus eremicus (Rose \& Zolnerowich; Hymenoptera: Aphelinidae) (Sugiyama et al. 2011; Sohrabi et al. 2012, 2013).

It is important to note that in our study, parasitized B. cockerelli nymphs were completely drenched with the insecticide solution; consequently, they were exposed to a much higher amount of the insecticides than under normal practice. Therefore, the acute toxicity caused by soybean oil, imidacloprid, and abamectin toward T. triozae may be associated with the following three factors. First, insecticides can cause immediate host death once they contact the host nymph body (Mahdavi et al. 2011, Sohrabi et al. 2013), as observed in the present study with abamectin, which caused total mortality of B. cockerelli nymphs at two (9 and $4.5 \mathrm{mg}[\mathrm{AI}] /$ liter) of the three concentrations evaluated. Second, after treatment, pesticides are deposited between the underside of the nymph and the leaf surface, which is the preferred location of the immature stages of T. triozae. Consequently, parasitoid mortality may occur through direct contact with the pesticide. Third, pesticides can cause indirect juvenile parasitoid mortality if the parasitoids develop outside of the host and feed on contaminated individuals (Kumar et al. 2008, Mahdavi et al. 2011). Accordingly, T. triozae eggs and larvae coated with soybean oil solution exhibited clear symptoms of dehydration, and larvae treated with imidacloprid and abamectin displayed tremors and paralysis.

T. triozae adult emergence was significantly reduced by the three insecticides tested, depending on the timing of the application, but no general pattern was detected. The decline in adult emergence caused by soybean oil, imidacloprid, and abamectin appeared to be dose dependent in some cases across all three developmental stages, and this effect was most evident in adults obtained from treated eggs and larvae. Variable results in terms of adult emergence have also been observed in other species of endoand ectoparasitoids when treated at different immature stages with imidacloprid, abamectin, and oil-based compounds. For example, in En. inaron (Sohrabi et al. 2012), both En. formosa and Er. eremicus (Sugiyama et al. 2011), and Er. mundus (Sohrabi et al. 2013), adult emergences were 15,45 , and $48 \%$, respectively, when treated at the pupal stage with these compounds. In contrast, $100 \%$ emergence was observed when $T$. radiata was treated at the pupal stage (Beloti et al. 2015).

In addition, when pupae were treated with abamectin, adult emergence was $35-41 \%$ (Ferrari 2009) for T. radiata and $58 \%$ for T. triozae (Luna-Cruz et al. 2011), whereas emergence was $\leq 1.5 \%$ in Eretmocerus warrae Naumann \& Schmidt (Hymenoptera: Aphelinidae) and Trichogramma chilonis Ishii (Hymenoptera: Trichogrammatidae) (Kumar et al. 2008, Hussain et al. 2010). Regarding oil-based compounds, an insecticide composed of saponified olive and neem oils (ratio 1.5:10) resulted in 54\% adult emergence in Aphidius colemani (Viereck; Hymenoptera: Braconidae) when treated as second-instar larvae in mummies of third to fourth instars of Myzus persicae (Sulzer; Hemiptera: Aphididae) (Tremblay et al. 2008). The differences observed between these studies and ours are most likely due to many factors, including the insecticide formulation and concentration, the host-parasitoid complex studied, the stage and behavior of the parasitoid (endo- or ectoparasitoid), and the methodology used for insecticide application.
When interpreting data on emergence rates from insecticidetreated hosts, it is also important to consider the fitness of the parasitoids that emerge (Smilanick et al. 1996). In our study, the sex ratio and adult longevity of T. triozae were examined to assess the sublethal effects of the tested insecticides. It has been reported that in T. triozae, the sex ratio normally favors females (range $86-88 \%$ ) (Morales et al. 2013, Rojas et al. 2015). When we treated T. triozae eggs, larvae, and pupae with soybean oil, imidacloprid, and abamectin, the proportion of females was not affected, except when the parasitoid was treated as larvae with the 50 or $100 \%$ MiFRC of soybean oil or when treated as pupae with the $\mathrm{LC}_{50}$ or $100 \%$ MiFRC of imidacloprid; in these cases, there were significantly more males than females. Given that no such effect was observed with the $50 \%$ MiFRC of imidacloprid, the biological significance of this finding remains unclear. Additionally, when the parasitoid A. melinus was treated as larvae with mineral oil (Biondi et al. 2015) or when Bracon nigricans (Szépligeti; Hymenoptera: Braconidae) was treated as pupae with emamectin benzoate (compound of the same family as abamectin, avermectins) (Biondi et al. 2013), the sex ratio favored females (64 and $81 \%$, respectively, for each parasitoid), as was observed in En. inaron (Sohrabi et al. 2012), T. pretiosum (Carvalho et al. 2003), Habrobracon hebetor (Say; Hymenoptera: Braconidae) (Rafiee et al. 2012), and A. ervi (Zuazúa et al. 2003) when treated with imidacloprid as larvae or pupae.

In contrast to our results, the number of males was higher in B. nigricans when pupae were treated with abamectin (Biondi et al. 2013), and the number of A. colemani males also increased following treatment at the pupal stage with an insecticide based on saponified olive and neem oils (Tremblay et al. 2008). Although the mechanisms by which these effects might be exerted are poorly understood, we hypothesize that they may be associated with several factors: the number and age of spermatozoids present in spermathecae; the death and reabsorption of spermatozoids; the number of copulations; and differential mortality of sexes in the larval stage (Holloway et al. 1999, Damiens et al. 2003).

Most studies about the effects of chemical insecticides on the longevity of parasitoid adults obtained from treated immature stages have addressed the longevity of females, and relatively little has been published regarding that of males (Rafiee et al. 2012; Sohrabi et al. 2012, 2013). We observed that the longevity of T. triozae adults was affected according to the concentration and type of insecticide applied and by the immature stage treated. However, no inter-sex differences were observed, with the exception of $810 \mathrm{mg}(\mathrm{AI}) /$ liter soybean oil and $260 \mathrm{mg}(\mathrm{AI}) / \mathrm{liter}$ abamectin, for which females obtained from both treated larvae and pupae lived 14-15 d longer than males. In another study, the longevity of adults of the endoparasitoid Bracon brevicornis (Wesmael; Hymenoptera: Braconidae) obtained from parasitized Spodoptera littoralis (Boisduval; Lepidoptera: Noctuidae) larvae was 1 and $2 \mathrm{~d}$ longer for females than males when treated at egg and larval stages, respectively, with the neonicotinoid compound thiamethoxam or thiacloprid at $1.5 \mathrm{mg}$ (AI)/liter (Tabozada et al. 2015).

Regardless, Kumar et al. (2008), reported that females of Er. warrae obtained from eggs, larvae, and pupae treated with $2 \mathrm{ml}$ (AI)/liter abamectin lived $1 \mathrm{~d}$ longer than males ( 3 vs. $2 \mathrm{~d}$ ). The only case we found in the literature showing a strongly unbalanced effect on longevity was that of the parasitoid B. nigricans, whereby female adults derived from pupae that developed with the host, Tuta absoluta (Meyrick; Lepidoptera: Gelechiidae), treated with 150 and $75 \mathrm{ml}$ (AI)/ liter emamectin benzoate and abamectin, respectively, lived $20 \mathrm{~d}$ longer than males (Biondi et al. 2013). It is important to note that the effects on 
T. triozae longevity reported herein may be underestimated because the tested insects were removed from the treated environment.

This study reports for the first time a more complete analysis of the lethal and sublethal effects of soybean oil, imidacloprid, and abamectin on T. triozae when treated at the egg, larval and pupal stages. Our results demonstrate that these compounds are not as selective to this parasitoid as initially thought. The impact of some of our experimental treatments on T. triozae varied with insecticide chemistry in terms of their modes of action, primarily regarding acute toxicity and sublethal effects such as the sex ratio and adult longevity. In Mexico, the use of T. triozae as a biological control agent in greenhouses is only just beginning. Therefore, our results should be considered before designing an integrated pest management (IPM) approach for B. cockerelli based on an augmentative strategy. In particular, the use of soybean oil, imidacloprid, and abamectin in combination with T. triozae may be effective when the parasitoid is in the pupal stage because this stage is less susceptible than the egg and larval stages.

\section{Acknowledgments}

S.I.M. received financial support from the Consejo Nacional de Ciencia y Tecnología, Mexico. This work was financially supported by the Coordinación de la Investigación Científica, Universidad Michoacana de San Nicolás de Hidalgo. We are grateful to American Journal Experts for reviewing the English style, which has contributed to clarifying the manuscript.

\section{References Cited}

Beloti, V. H., A. G. Rodriguez, A. D. F. Dias, P. M. Manara, R. A. Moral, D. C. G. Borges, and Y. P. Takao. 2015. Lethal and sublethal effects of insecticides used on citrus, on the ectoparasitoid Tamarixia radiata. PLoS One 10: e0132128.

Biondi, A., L. Zappalà, J. D. Stark, and N. Desneux. 2013. Do biopesticides affect the demographic traits of a parasitoid wasp and its biocontrol services through sublethal effects? PLoS One 8: e76548.

Biondi, A., O. Campolo, N. Desneux, G. Siscaro, V. Palmeri, and L. Zappalà. 2015. Life stage-dependent susceptibility of Aphytis melinus DeBach (Hymenoptera: Aphelinidae) to two pesticides commonly used in citrus orchards. Chemosphere 128: 142-147.

Bujanos, M. R., T. J. A. Garzón, and J. A. Marín. 2005. Manejo integrado del pulgón saltador Bactericera (=Paratrioza) cockerelli (Sulc.) (Hemiptera: Triozidae) en los cultivos de solanáceas en México, pp. 93-98. In Segunda Convención Mundial del Chile (Mexico), 14-16 August 2005, Zacatecas, Zacatecas, México.

Carvalho, G. A., P. R. Reis, L. C. D. Rocha, J. C. Moraes, L. C. Fuini, and C. C. Ecole. 2003. Side-effects of insecticides used in tomato fields on Trichogramma pretiosum (Hymenoptera, Trichogrammatidae). Maringá 25: 275-279.

Damiens, D., C. Bressac, and C. Chevrier. 2003. The effects of age on sperm stock and egg laying in the parasitoid wasp, Dinarmus basalis. J. Insect Sci. 3: 1-5.

Dávila, M. M. D., C. E. Cerna, U. L. A. Aguirre, M. O. García, F. Y. M. Ochoa, M. G. Gallegos, and F. H. Landeros. 2012. Susceptibility and resistance mechanisms to insecticides in Bactericera cockerelli (Sulc.) in Coahuila, Mexico. Rev. Mex. Cienc. Agric. 6: 1145-1155.

Desneux, N., A. Decourtye, and J. M. Delpuech. 2007. The sublethal effects of pesticides on beneficial arthropods. Annu. Rev. Entomol. 52: 81-106.

Ferrari, B. M. 2009. Efeitos letais e subletais de insecticidas sobre Tamarixia radiata (Waterston, 1922) (Hymenoptera: Eulophidae). M.S thesis. Escola Superior de Agricultura "Luiz de Queiroz", Universidad de Sao Paulo, Sao Paulo, Brazil.

Gharalari, A. H., C. Nansen, D. S. Lawson, J. Gilley, J. E. Munyaneza, and K. Vaughn. 2009. Knockdown mortality, repellency, and residual effects of insecticides for control of adult Bactericera cockerelli (Hemiptera: Psyllidae). J. Econ. Entomol. 102: 1032-1038.

Hassan, S. A. 1977. Standardized techniques for testing side-effects of pesticides on beneficial arthropods in the laboratory. J. Plant Dis. Prot. 84: 158-163.

Holloway, A. K., G. E. Heimpel, M. R. Stand, and F. Antolin. 1999. Survival of diploid males in Bracon sp. near hebetor (Hymenoptera: Braconidae). Ann. Entomol. Soc. Am. 92: 110-116.

Hussain, D., M. Akram, Z. Iqbal, A. Ali, and M. Saleem. 2010. Effect of some insecticides on Trichogramma chilonis (Ishii) (Trichogrammatidae: Hymenoptera) immature and adult survival. J. Agric. Res. 4: 531-537.

(IRAC) Insecticide Resistance Action Committee. 2017. The IRAC mode of action classification. http://www.irac-online.org/modes-of-action/.

Kumar, P., M. Whitten, G. Thoeming, C. Borgemeister, and H. M. Poehling. 2008. Effects of bio-pesticides on Eretmocerus warrae (Hymenoptera: Aphelinidae), a parasitoid of Bemisia tabaci (Homoptera: Aleyrodidae). J. Appl. Entomol. 132: 605-613.

Lasota, J. A., and R. A. Dybas. 1991. Avermectins, a novel class of compounds: implications for use in arthropod pest control. Annu. Rev. Entomol. 36: 91-117.

Lee, K., S. J. Chung, and G. Chung. 2005. Effectiveness of bionatrol on control of two spotted spider mites (Tetranychus urticae), aphids (Aphis gossypii), and whiteflies (Trialeurodes vaporariorum) on greenhouse grown English cucumber (Cucumis ssp. kasa). J. Kor. Soc. Hort. Sci. 46: 241-245.

Levy, J., A. Ravindran, D. Gross, C. Tamborindeguy, and E. Pierson. 2011. Translocation of "Candidatus Liberibacter solanacearum", the zebra chip pathogen, in potato and tomato. Bacteriology 101: 1285-1291.

Liu, T. X., Y. M. Zhang, L. N. Peng, P. Rojas, and J. T. Trumble. 2012. Risk assessment of selected insecticides on Tamarixia triozae (Hymenoptera: Eulophidae), a parasitoid of Bactericera cockerelli (Hemiptera: Triozidae). J. Econ. Entomol. 105: 490-496.

Luna-Cruz, A., R. Lomelí-Flores, E. Rodríguez-Leyva, L. D. Ortega-Arenas, and A. Huerta-De la Peña. 2011. Toxicidad de cuatro insecticidas sobre Tamarixia triozae (Burks) (Hymenoptera: Eulophidae) y su hospedero Bactericera cockerelli (Sulc) (Hemiptera: Triozidae). Acta. Zool. Mex. (n.s.). 27: 509-526.

Luna-Cruz, A., E. Rodríguez-Leyva, R. Lomelí-Flores, L. D. Ortega-Arenas, N. Bautista-Martínez, and S. Pineda 2015. Toxicity and residual activity of insecticides against Tamarixia triozae (Hymenoptera: Eulophidae), a parasitoid of Bactericera cockerelli (Hemiptera: Triozidae). J. Econ. Entomol. 108: 2289-2295.

Mahdavi, V., M. Sabe, D. H. Rafiee, and A. Mehrvar. 2011. Comparative study of the population level effects of carbaryl and abamectin on larval ectoparasitoid Habrobracon hebetor Say (Hymenoptera: Braconidae). BioControl 56: 823-830.

Martínez, A. M., K. B. Caudillo, S. I. Morales, J. I. Figueroa, J. M. Chavarrieta, R. Bujanos, O. Gómez, E. Viñuela, and S. Pineda. 2015. Behavior of Tamarixia triozae females (Hymenoptera: Triozidae) and effects of pesticides on this parasitoid. Environ. Entomol. 44: 3-11.

Morales, A. S. I., A. M. Martínez, J. I. Figueroa, A. M. H. Espino, J. M. Chavarrieta, R. Ortiz, C. L. Rodríguez-Enríquez, and S. Pineda. 2013. Parámetros de vida del parasitoide sinovigénico Tamarixia triozae (Hymenoptera: Eulophidae). Rev. Colomb. Entomol. 39: 243-249.

Munyaneza, J. E., and V. G. Sengoda. 2009. First report of "Candidatus Liberibacter solanacearum" in pepper plants in México. Plant Dis. 93: 1076.

Munyaneza, J. E., J. M. Crosslin, and E. J. Upton. 2007. Association of Bactericera cockerelli (Homoptera: Psyllidae) with "zebra chip", a new potato disease in Southwestern United States and Mexico. J. Econ. Entomol. 100: 656-663.

Pless, C. D., D. E. Deyton, and C. E. Sams. 1995. Control of San Jose scale, terrapin scale, and European red mite on dormant fruit trees with soybean oil. Hortic. Sci. 20: 94-97.

Rafiee, D. H., M. Hassanpour, G. G. Nouri, A. Golizadeh, and S. Sarmadi. 2012. Sublethal effects of indoxacarb, imidacloprid and deltamethrin on life table parameters of Habrobracon hebetor (Hymenoptera: Braconidae) in pupae stage treatment. J. Crop. Prot. 1: 221-228. 
Rojas, P., E. Rodríguez-Leyva, J. R. Lomelí-Flores, and T. X. Liu. 2015. Biology and life history of Tamarixia triozae, a parasitoid of the potato psyllid Bactericera cockerelli. BioControl 60: 27-35.

Santos, M. S., O. Z. Zanardi, K. S. Pauli, M. R. Forim, P. T. Yamamoto, and J. D. Vendramim. 2015. Toxicity of an azadirachtin-based biopesticide on Diaphorina citri Kuwayama (Hemiptera: Liviidae) and its ectoparasitoid Tamarixia radiata (Waterston) (Hymenoptera: Eulophidae). Crop Prot. 74: 116-123.

Smilanick, J. M., F. G. Zalom, and L. E. Ehler. 1996. Effects of metamidophos residue on the pentatomid egg parasitoids Trissolcus basalis and T. utahensis (Hymenoptera: Scelionidae). Biol. Control 6: 193-201.

Sohrabi, F., P. Shishehbor, M. Saber, and M. M. Said. 2012. Lethal and sublethal effects of buprofezin and imidacloprid on the whitefly parasitoid Encarsia inaron (Hymenoptera: Aphelinidae). Crop Prot. 32: 83-89.

Sohrabi, F., P. Shishehbor, M. Saber, and M. M. Said. 2013. Lethal and sublethal effects of buprofezin and imidacloprid on the sweet potato whitefly parasitoid Eretmocerus mundus (Hymenoptera: Aphelinidae). Crop Prot. 45: 98-103.

Stansly, P. A., and T. X. Liu. 1997. Selectivity of insecticides to Encarsia pergandiella (Hymenoptera: Aphelinidae), an endoparasitoid of Bemisia argentifolii (Hemiptera: Aleyrodidae). Bull. Entomol. Res. 87: 525-531.
Sugiyama, K., H. Katayama, and T. Salto. 2011. Effect of insecticides on the mortalities of three whitefly parasitoid species, Eretmocerus mundus, Eretmocerus eremicus and Encarsia formosa (Hymenoptera: Aphelinidae). Appl. Entomol. Zool. 46: 311-317.

Tabozada, E. O., S. M. Sayed, and S. A. El-Arnaouty. 2015. Side effects of sublethal concentration of two neonicotinoids; thiamethoxam and thiacloprid on the larval parasitoid, Bracon brevicornis (Hymenoptera: Braconidae). Am. J. Exp. Agric. 5: 29-35.

Tremblay, E., A. Bélanger, M. Brosseau, and G. Boivin. 2008. Toxicity and sublethal effects of an insecticidal soap on Aphidius colemani (Hymenoptera: Braconidae). Pest Manag. Sci. 64: 249-54.

Yang, X. B., Y. M. Zhan, L. Hua, and T. X. Liu. 2010. Life history and life table of Bactericera cockerelli (Hemiptera: Psyllidae) on potato under laboratory and field conditions in the lower Rio Grande Valley of Texas. J. Econ. Entomol. 103: 1729-1734.

Zhang, A., H. Kayser, P. Maienfisch, and J. F. Casida. 2000. Insect acetylcholine receptor: conserved neonicotinoid specificity of $\left[{ }^{3} \mathrm{H}\right]$ imidacloprid binding site. J. Neurochem. 3: 1294-1303.

Zuazúa, F., J. E. Araya, and M. A. Guerrero. 2003. Efectos letales de insecticidas sobre Aphidius ervi Haliday (Hymenoptera: Aphididae), parasitoide de Acyrthosiphon pisum (Harris) (Homoptera: Aphididae). Bol. San. Veg. Plagas 29: 299-307. 